\title{
TITULARES, BALAZOS, LLAMADAS Y FOTOGRAFÍAS: SuiCidio EN TRES PERIÓdicos DE MÉRIdA, YuCATÁn, MÉXICO, EN EL 2015
}

\author{
HEADLINES, LURES AND SECONDARY LEADS: SUICIDE IN \\ THREE NEWSPAPERS OF MÉRIDA, YuCATÁN, MÉXICO, IN
}

2015

\section{Laura Hernández Ruiz ${ }^{\star}$}

Resumen: Se realizó un análisis de encabezados, fotos y notas al pie, en tres periódicos de Yucatán, México: ¡Al chile!, De Peso y Por Esto!, publicados entre el $1^{\circ}$ de enero y el 30 de junio de 2015 , con objeto de encontrar evidencias sobre diversos elementos lingüísticos y semióticos utilizados para recrear la realidad y funcionar como intermediaria entre diversos actores sociales, y con ello determinar la forma como interactúan y revisar su efecto. Una de las razones fundamentales de esta pesquisa es que algunos medios de información impresa no observan las recomendaciones de la OMS al reportar los suicidios. Motivo de preocupación ya que, según INEGI, Yucatán ha ocupado los primeros lugares de autoeliminación en México. Entre los resultados se suman el logro de consenso del lector por medio del uso de valores y configuraciones simbólicas, así como una estructuración de la percepción del receptor y de modelos conceptuales a través de metáforas, prosopopeya y erotemas, entre otros; amén de la abundancia de fotografías donde incluso algunas presentan al difunto in situ.

\footnotetext{
* Profesora Titular "B" de Tiempo Completo, Centro Peninsular en Humanidades y Ciencias Sociales (CEPHCIS), Universidad Nacional Autónoma de México. Correo electrónico: laheru@hotmail.com

Fecha de recepción: 2801 19; 2a. versión: 2603 19; Fecha de aceptación: 300519.
}

(cc) BY-NC-ND Páginas 203-232

julio-diciembre 2019, vol. 6

núm. 2 (13) ISSN: 2007-7610 
Palabras clave: Análisis del discurso, elementos lingüísticos y semióticos, medios impresos de comunicación, suicidio.

Abstract: An analysis of headings, photos and footnotes was conducted in three newspapers in Yucatan, Mexico: ¡Al chile!, De Peso and Por Esto!, published between January 1st and June 30, 2015, so to find evidence on various linguistic and semiotic elements used to recreate reality and function as a link between different social actors, in order to determine how they interact and check their effect. This research was motivated by the lack of attention that some reporters put in writing notes about suicide without considering the recommendations given by the WHO. It is a cause of concern because, according to INEGI, Yucatán has occupied the first places of selfelimination in Mexico. Among the results we can sum the readers consensus achievement through the use of values and symbolic configurations, as well as a structuring of the receivers perception and conceptual models through metaphors, prosopopeia and rhetoric questions, among others; in addition to the abundance of photographs where even some exhibit the deceased in situ.

Keywords: Discourse analysis, linguistic and semiotic elements, print media, suicide.

\section{Introducción}

El suicidio es uno de los problemas que aqueja a la población yucateca, de hecho hay quienes al hablar del fenómeno y desconociendo las cifras, aseguran que Yucatán tiene el primer lugar en suicidios de la República Mexicana. Y es que la población está al tanto de estos acontecimientos a través de los medios informativos, que se encargan de comunicarlos oportunamente. No obstante, la prensa escrita se vale de diversos elementos, entre ellos los lingüísticos y semióticos, para recrear la realidad y funcionar como intermediaria entre diversos actores sociales. Con objeto de encontrar evidencias sobre estos elementos, determinar la forma como interactúan y revisar su efecto, en este estudio se analiza el discurso de los encabezados sobre el suicidio de tres rotativos de Mérida, Yucatán, México: ¡Al chile!, De Peso y Por Esto! 
Vale la pena aclarar que el estudio fue motivado por tres situaciones principales: La primera se relaciona con el alto índice de suicidios en el estado de Yucatán, el cual ocupa los primeros lugares dentro de los estados de la República Mexicana, según el Instituto Nacional de Estadística y Geografía (INEGI). De hecho, en los últimos años, su presencia entre los primeros doce estados de la República Mexicana con los índices más altos de suicidios, ha sido constante. Los datos del INEGI señalan que en el 2011 el estado ocupaba el onceavo lugar con 186 casos, mientras que en el 2009 tenía el octavo con 219.

La segunda tiene que ver con una publicación de la Organización Mundial de la Salud (OMS) en el año 2000. En ella se incluyen algunos elementos léxico-icónicos que deben evitarse al reportar un caso de autoeliminación, como el discurso sensacionalista, las fotografías de los suicidas, la descripción detallada del método utilizado y la escena del suicidio, así como la exaltación de los suicidas o el suicidio, entre otros.

$\mathrm{La}$ tercera, por los resultados de investigaciones realizadas en diferentes países, además de una en Mérida, Yucatán, las cuales sostienen que la forma como los medios reportan los casos de autodestrucción puede ser vista como detonadora del potencial suicida pre-existente en algunas personas. Esto es, cuando las condiciones suicidógenas son altas, como en casos severos de depresión, pesimismo, estrés y baja autoestima (Stack y Haas 1984: 20). La preocupación surge de casos documentados sobre la relación entre los medios y el suicidio. Según Schmidtke (2002: 6), el primer registro se puede ver con la novela de Goethe The Sorrows of Young Werther, publicada en 1774, obra en la que el héroe se dispara tras un amor frustrado. Poco tiempo después de la publicación hubo muchos reportes de jóvenes lectores utilizando el mismo método para suicidarse, lo que provocó la prohibición de la novela en varios lugares. Otro caso registrado, según Marzuk (1993: 6), es el de la obra Final Exit, escrita por Derek Humphry, a cuya publicación le siguió un aumento en el número de suicidios en Nueva York, utilizando el procedimiento descrito, suicidio asistido. Soubrier (1984: 40) comenta que cuando se publicó su traducción en Francia, Suicide, mode d'emploi, también se incrementó el número de suicidios, utilizando el mismo sistema. Por otro lado, Muchembled (2002: 310) señala que el grupo musical de origen inglés, Judas Priest, fue llevado a la justicia por incitación al suicidio, debido a que el 23 de diciembre 
de 1985, durante una noche de droga y alcohol, dos adolescentes se dispararon una bala en la cabeza después de oír su interpretación de la canción grabada en 1978, Better by you, better than me. En todos los casos citados los receptores vulnerables fueron víctimas de las representaciones transmitidas por los diferentes medios.

También, según Philips et al (1992: 500), se ha reportado que el grado de publicidad que se da a un suicidio está directamente relacionado con el número de autodestrucciones subsecuentes. Philips (1982: 1341) demostró que hay un incremento en el número de suicidios dentro de los diez días posteriores al reporte de un suicidio en la televisión; así como de las historias más publicadas, en especial si hay celebridades involucradas.

A esto se suma un estudio realizado con jóvenes de la subcomisaría de Chichí Suárez, Yucatán, México, sobre la percepción del suicidio (Hernández 2011). Éste reveló, tras la lectura de varios noti-reportajes relacionados con este fenómeno, el estado de anomia, angustia, desconcierto e indefensión que viven día a día, así como la apropiación de algunas ideas vertidas por la prensa, por ejemplo percibir el suicidio (muerte) como la salida o puerta de huida del caos en el que viven.

Ahora bien, para tener un panorama más claro de la situación, se inicia con datos estadísticos sobre este fenómeno, algunos tomados de los anuarios del Instituto Nacional de Estadística Geografía e Informática (INEGI) y otros proporcionados directamente por la Procuraduría General de Justicia del Estado de Yucatán (PGJEY). Se recomienda estudiar las cifras con ciertas reservas ya que, particularmente en el caso del suicidio, las estadísticas son muy erráticas, debido a una manipulación errónea o sesgada por parte de los capturistas, una averiguación inconclusa por parte de las instancias correspondientes o inclusive por el ocultamiento voluntario de los propios familiares y amigos.

La presencia de Yucatán entre los primeros 14 estados de la República Mexicana con los índices más altos de suicidios ha sido constante. En la tabla siguiente se aprecia el número de suicidios registrados por el INEGI de 2001 al 2014, así como la posición que ocupa, en contraste con los otros estados del territorio nacional. Es importante señalar que anteriormente el Registro Civil se encargaba de llevar el inventario de suicidios en el estado; sin embargo, la PGJEY debe realizar una investigación concienzuda de cada uno de estos 
acontecimientos, tarea que en ocasiones además de tomar demasiado tiempo al final revelaba que lo que se había registrado como suicidio era realmente un homicidio o viceversa. Por ello, para evitar diferencias en las cifras es la PGJEY quien se encarga de este manejo estadístico.

Tabla 1: Suicidios según INEGI (2001-2014)

\begin{tabular}{|c|c|c|}
\hline Año & Número de suicidios & Posición en la República \\
\hline 2001 & 93 & $12^{\text {o }}$ \\
\hline 2002 & 129 & $8^{\circ}$ \\
\hline 2003 & 162 & $8^{\circ}$ \\
\hline 2004 & 138 & $9^{\circ}$ \\
\hline 2005 & 134 & $10^{\circ}$ \\
\hline 2006 & 151 & $12^{\circ}$ \\
\hline 2007 & 140 & $14^{\circ}$ \\
\hline 2008 & 160 & $11^{\circ}$ \\
\hline 2009 & 219 & $8^{\circ}$ \\
\hline 2010 & 206 & $8^{\circ}$ \\
\hline 2011 & 186 & $11^{\circ}$ \\
\hline 2012 & 159 & $14^{\circ}$ \\
\hline 2013 & 172 & $11^{\circ}$ \\
\hline 2014 & 181 & $12^{\circ}$ \\
\hline
\end{tabular}

Elaboración propia con base en datos estadísticos de INEGI 2001 a 2014

Dicha preocupación por el incremento de suicidios en Yucatán ha promovido, de alguna manera, el surgimiento de diferentes organizaciones que tienen como objetivo brindar ayuda a las personas que se encuentran en estado de desesperanza y que ven el suicidio como única alternativa. Así, durante la administración del Gobernador Constitucional del Estado, el Ciudadano Federico Granja Ricalde, Alis García Gamboa fundó la asociación civil "Salvemos una Vida A. C.", el 10 de julio de 1995, la cual da asistencia emocional y espiritual, de manera gratuita y personal, o a través de su programa de radio, a las personas que llegan en crisis (De Anda, 2015). Del mismo 
modo, está el "Programa Integral de Atención al Suicidio de Yucatán" (PIAS), creado y coordinado por el Dr. Gaspar Baquedano López, con una larga trayectoria como suicidólogo. Este programa cuenta con un grupo terapéutico "La Esperanza", integrado por un grupo de personas que tienen en común haber intentado suicidarse o haber sufrido la pérdida de algún ser querido por este medio. También, según el documento titulado Catálogo de Programas de Bienes y Servicios Públicos 2015, hay uno de la Secretaría de Salud de Yucatán (SSY), llamado "Programa de Atención a la Depresión y Prevención del Suicidio” (PDS) (Secretaría de Salud de Yucatán. 2018). Así también se suma el grupo Murmurante, un colectivo de creación e investigación escénica sin fines de lucro, cuyo propósito es hacer del arte escénico un vehículo idóneo para producir y difundir conocimiento, diálogo y reflexión sobre problemáticas sociales que impactan cotidianamente la realidad de nuestra región. Fundado en el 2008 por Ariadna Medina y Juan de Dios Rath (Murmurante. s/f).

Inscrito en este contexto, este artículo pretende sumergirse en el discurso de los encabezados sobre el suicidio en la prensa escrita, para identificar los elementos lingüísticos y semióticos utilizados para informar a la población. Para la selección de la muestra se tomó en consideración un estudio previo, realizado en Yucatán, entre 2004 y 2006, el cual revela que el promedio de muertes ocurridas por autoeliminación fue mayor en los meses de marzo, abril, y junio. Luego, el corpus de este estudio lo conforman todos los materiales publicados entre el $1^{\circ}$ de enero y el 30 de junio de 2015. Esto incluye: 90 titulares, 35 subtitulares, 25 balazos $^{1}$ y 18 llamadas $^{2}$. Más adelante, en la perspectiva teórico-metodológica se abunda sobre el medio de comunicación impreso seleccionado para este trabajo y se explican, de manera muy general, algunas de las estrategias que deben evitarse al dar cobertura al suicidio.

\footnotetext{
${ }^{1}$ El balazo es la idea debajo del encabezado y debe introducir nuevos elementos informativos, según la página electrónica Nuevos Periodistas (Gálvez Vidal, Germán. 2010). También coincide con la definición de Joaquín Pérez (Taller de redacción, 2009): Cuando se agrega al titular, en letras más pequeñas y sobre él, una palabra o frase se da el nombre de balazo.

${ }^{2}$ Según el sitio Media Prensa del Ministerio de Educación del Gobierno de España, las "llamadas" estarían dentro de la categoría de títulos y subtítulos: "La noticia consta de tres partes: títulos, entradilla o lead y cuerpo de la información. Los títulos (titular y subtítulos) son la llamada de atención del lector, lo que va a captar su atención. La entradilla viene a ser el núcleo, la esencia de la información, es el párrafo inicial que resume los datos más importantes. El cuerpo desarrolla lo anticipado en la entradilla, ampliando esos datos e introduciendo otros nuevos" (Ministerio de educación. s/f)
} 
Tabla 2: Meses en los que se registraron más suicidios entre 2004 y 2006

\begin{tabular}{|c|c|c|}
\hline Posición & Mes & Número (promedio) \\
\hline $1^{\text {o }}$ & Abril & 13.3 \\
\hline $2^{\circ}$ o & Mayo / Agosto & 12.3 \\
\hline $3^{\circ}$ & Marzo / Julio & 12 \\
\hline $4^{\circ}$ & Junio & 11.6 \\
\hline $5^{\circ}$ & Septiembre & 11.3 \\
\hline
\end{tabular}

Elaboración propia con base en los datos proporcionados por la PGJY.

\section{Perspectiva teórico-metodológica}

El análisis se hace desde la dimensión pragmática, siguiendo el modelo a tres niveles del sociólogo español Jesús Ibáñez (1978), comentado por Jociles Rubio (2005). Así, se realiza el análisis nuclear, dentro del cual se revisan la verosimilitud referencial, lógica, poética y tópica; seguido del análisis autónomo y, como colofón, el total. Para aproximarnos al conocimiento de este fenómeno discursivo, el corpus quedó conformado por jAl chile!, De Peso y Por Esto! Preciso resaltar que se escogieron dichos rotativos pues, de acuerdo con la Asociación de Editores de los Estados, México, son tres de los más vendidos en Yucatán. Su circulación en 2015 era de 86,000 De Peso; 40,000 ;Al Chile! y 30,000 Por Esto! Luego, según el Padrón Nacional de Medios Impresos (Secretaría de Gobernación, 2018) el nivel socioeconómico de lectores de estos diarios era como sigue:

Tabla 3: Nivel socioeconómico de lectores de los tres diarios

\begin{tabular}{|c|c|}
\hline Periódico & \multicolumn{2}{|c|}{ Nivel socioeconómico de lectores (NSE) } \\
\hline \multirow{3}{*}{ De Peso } & $\mathrm{B}: \quad 11 \%$ \\
& $\mathrm{C}: \quad 73 \%$ \\
& $\mathrm{D}: \quad 16 \%$ \\
\hline \multirow{3}{*}{ Al Chile! } & $\mathrm{ABC}+: \quad 11 \%$ \\
& $\mathrm{C}: \quad 15 \%$ \\
& $\mathrm{D}+: \quad 39 \%$ \\
\hline Por Esto! & DE: $\quad 35 \%$ \\
\hline
\end{tabular}

Fuente: Padrón Nacional de Medios Impresos 2016 (Secretaría de Gobernación, 2018) 
Donde hay seis niveles: Nivel E, hasta 60 puntos (Pobreza extrema); Nivel D, entre 61 y 101 (Clase pobre); Nivel D+, entre 102 y 156 (Clase media baja); Nivel C, entre 157 y 191 (Clase media); Nivel C+, entre 192 y 241 (Clase media alta); Nivel A/B, entre 242 y más (Clase alta o rica).

Sobra decir que los involucrados de manera activa en esta función diaria son los dueños y directivos de los rotativos, cuya labor es procurar el intercambio de información oportuna de sucesos de interés público a cambio de un capital económico. Se suman a éstos los reporteros, que en ocasiones permanecen en el anonimato, quienes intercambian sus servicios de búsqueda, redacción y tomas fotográficas de la noticia, por recursos financieros; y los lectores, que deciden asignar una parte de su ingreso económico para la adquisición de un ejemplar del periódico de su elección.

Antes de continuar, debo subrayar que los tres diarios de referencia cumplen con su propósito fundamental, la comunicación oportuna de acontecimientos de interés público. No obstante, no se puede soslayar la seducción del intercambio mercantil implícito, restringido por la caducidad de la noticia y preferencia de los lectores, lo cual estimula que los reporteros y editores integren, en su re-presentación de la realidad, creencias valorativas e ideológicas para promover la venta de sus diarios, construyendo y difundiendo un sentido hegemónico de "la realidad" que reportan. La cual puede influir, de manera unidireccional, en la competencia modal de las personas susceptibles, esto es, el estado de creer, querer y saber de algunos lectores, dada la plasticidad del proceso de percepción (factores internos y externos de cada individuo).

Asimismo, es preciso señalar que el tipo de publicaciones que presentan los rotativos de referencia sobre el suicidio es un híbrido, pues con frecuencia estas son demasiado prolijas, muy creativas, cargadas de elementos reiterativos, discursivos y sobrelocuentes, y poco objetivas como para ser notas informativas $\mathrm{y}$, otras veces, carentes de investigación formal y apuntes tomados in situ (como un autor-testigo de los hechos) como para ser reportajes, por lo que en este trabajo se les denomina noti-reportajes.

De entrada, se hace hincapié en que actualmente algunos periódicos, que procuran día a día obtener mejores resultados en la actividad de compra-venta de información impresa, parecen concebir la autoeliminación como parte de un discurso que se ofrece como un valor agregado a la mercancía informativa. 
De ahí que, de vez en cuando llegan a registrarse más publicaciones sobre suicidio de los que realmente tienen lugar en la entidad, pues se reporta un caso hasta dos veces en el mismo diario, en diferente día.

Tabla 4: Número de publicaciones sobre suicidios

\begin{tabular}{|c|c|c|c|}
\hline Diario & $\begin{array}{c}\text { Suicidios } \\
\text { publicados } \\
\text { una vez }\end{array}$ & $\begin{array}{c}\text { Suicidios } \\
\text { publicados } \\
\text { dos veces }\end{array}$ & $\begin{array}{c}\text { Número bruto } \\
\text { de suicidios } \\
\text { reportados }\end{array}$ \\
\hline De peso & 25 & 2 & 27 \\
\hline Por Esto! & 45 & 1 & 46 \\
\hline iAl chile! & 18 & 0 & 18 \\
\hline
\end{tabular}

Elaboración propia con base en el análisis de los rotativos (enero-junio de 2015).

Cabe destacar que los noti-reportajes sobre el suicidio tienen una sección especial dentro de cada diario; en el De peso aparecen en Alerta Roja, en jAl chile! en la jAlarma! y en el caso del Por Esto! en las secciones Policía o Yucatán. La de Policía siempre va al final de Ciudad, ya que incluye la información de última hora y en ella se consignan las violaciones a la ley o cualquier otro acontecimiento que desquicie el orden social establecido como: crímenes, choques, robos, asaltos, fraudes, riñas, violaciones y, una que otra vez, suicidios. Mientras que en Yucatán se incluye casi todo tipo de información, organizada por los diferentes municipios del estado. Como se aprecia a continuación, en lo que va del año, se ha privilegiado la sección Yucatán.

En cuanto a la asignación de páginas para la inclusión de información sobre el suicidio, mientras De peso privilegia las páginas 11 a la 20 , jAl chile! prefiere las primeras 10 y en el Por Esto!, la sección de Policía se inserta entre las primeras y las últimas 10. La razón para esto la explica Demián, uno de los reporteros de este diario, quien advierte que "las dos primeras páginas se destinan a grandes personalidades" (los suicidas pobres no se incluyen en esta sección), el resto se organiza más o menos por espacio, aunque las últimas procuran consagrarlas a "fotos espectaculares a color", de accidentes, suicidios o algún otro suceso perturbador. También, es importante resaltar que el número de columnas asignadas a los suicidios en los rotativos estudiados varía; así, entre el 33 y el 61\% de las publicaciones se presentan en más de cuatro 
columnas, "para poder abundar en detalles, como le gusta a la gente", según aclara uno de los reporteros; mientras que entre el 26 y el $48 \%$ se redactan en una o dos.

Tabla 5: Número de columnas asignadas a los suicidios

\begin{tabular}{|c|c|c|c|}
\hline Columnas & De peso & Por Esto! & ;Al chile! \\
\hline $\mathbf{1}$ & 7 & 0 & 3 \\
\hline $\mathbf{2}$ & 6 & 12 & 3 \\
\hline $\mathbf{3}$ & 5 & 10 & 1 \\
\hline $\mathbf{4}$ & 7 & 0 & 5 \\
\hline $\mathbf{5}$ & 1 & 21 & 3 \\
\hline $\mathbf{6}$ & 0 & 0 & 1 \\
\hline $\mathbf{7}$ & 1 & 1 & 1 \\
\hline $\mathbf{8}$ & 0 & 2 & 1 \\
\hline
\end{tabular}

Elaboración propia con base en el análisis de los rotativos (enero-junio de 2015).

Por otro lado, el lenguaje discursivo -verbal- no es el único medio que utiliza la prensa. Entre las técnicas que se han puesto al servicio del periodismo contemporáneo de manera avanzada, completa y eficaz, se suma la fotografía pues sus cualidades reproductivas y de impresión le permiten gran elocuencia. La fotografía es un enunciado visual cargado de motivaciones, intenciones, creencias, expectativas, reacciones y convenciones comunicativas (Pericot, 2002:27). Conviene aclarar que, por cuestiones de ética y respeto a los suicidas y en estricto apego al objetivo general de esta pesquisa, se han evitado las fotografías, incluyendo sólo los elementos cuantitativos y algunas descripciones cualitativas para guiar al lector.

La fotografía cumple un papel importante en la elaboración de la noticia y su legitimación, ya que recoge una prueba del suceso in situ y su pertinencia radica en la captación espontánea del instante, una evidencia de que el suceso fotografiado existió, según señala Berger, (2007: 86). Hay que hacer notar que Verón (1980) observó que la mirada de los periodistas juega un papel importante en los medios, pues produce una puesta en escena, en la que el ocultamiento y la exhibición se potencian para producir con eficacia lo 
"real". Así, entre el 33 y el 36\% de las publicaciones sobre el suicidio aparecen sin fotografías, tal como sugiere la OMS; no obstante, entre el 64 y el 66\% restante exhibe de una hasta cinco fotos en el 2015.

Tabla 6: Número de fotografías incluidas en cada noti-reportaje

\begin{tabular}{|c|c|c|c|c|c|c|}
\hline No. Fotos & $\mathbf{0}$ & $\mathbf{1}$ & $\mathbf{2}$ & $\mathbf{3}$ & $\mathbf{4}$ & $\mathbf{5}$ \\
\hline De peso & 9 & 14 & 3 & 1 & & \\
\hline Por Esto! & 17 & 12 & 10 & 4 & 1 & 2 \\
\hline iAl chile! & 6 & 3 & 1 & 6 & 2 & \\
\hline
\end{tabular}

Elaboración propia con base en el análisis de los rotativos (enero-junio de 2015).

Hay que decir que éstas se distinguen por la selección de escenarios, los actores involucrados y las intenciones de los reporteros. Hay entre un nueve y un $18 \%$ en las que se presenta al suicida in situ, todavía pendiendo, en caso de ahorcamiento; en ocasiones hay algunas que, además del ahorcado, incluyen a los espectadores para que el receptor tenga una visión completa del escenario. Unas más en las que se muestra al occiso descubierto, en el piso. Otras en que probablemente el reportero llegó tarde y todavía encuentra al cadáver, pero ya está cubierto con una sábana o lo están sacando los del Servicio Médico Forense en una bolsa (tres al 10\%). Otras más donde -por no poder fotografiar al suicida o llegar tarde a la escena-, pero "con el deseo" de entregar a sus lectores "lo mejor", insertan una o varias imágenes del último espacio que ocupó el difunto, como un testigo silencioso del posible dolor del occiso y su última batalla. Finalmente están -en las que por no permitirse el ingreso a la prensael periodista no tiene más que fotografiar a los cuerpos policiacos, personal del SEMEFO y a los "curiosos", para no quedarse con "las ganas" de agregar una gráfica a su noti-reportaje. Todo esto lo hacen porque, según comenta uno de los reporteros entrevistados, "las fotos son muy impresionantes, muy atractivas", "mientras más dramáticas y más crueles y más ... es lo que le gusta a la gente". 
Tabla 7: Información incluida en las fotografías

\begin{tabular}{|c|c|c|c|c|c|c|c|}
\hline & 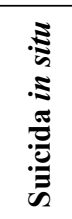 & 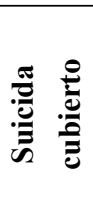 & 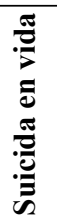 & 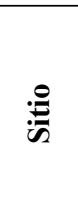 & 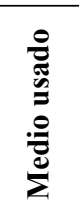 & 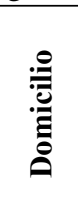 & 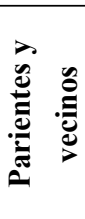 \\
\hline \multirow[t]{2}{*}{ De peso } & 12 & 2 & 0 & 18 & 10 & 18 & 4 \\
\hline & $18 \%$ & $3 \%$ & - & $28 \%$ & $15 \%$ & $28 \%$ & $6 \%$ \\
\hline \multirow[t]{2}{*}{ Por Esto! } & 16 & 9 & 0 & 24 & 9 & 22 & 10 \\
\hline & $17 \%$ & $10 \%$ & - & $26 \%$ & $10 \%$ & $24 \%$ & $11 \%$ \\
\hline \multirow[t]{2}{*}{ ¡Al chile! } & 9 & 6 & 0 & 11 & 8 & 13 & 53 \\
\hline & $9 \%$ & $6 \%$ & - & $11 \%$ & $8 \%$ & $13 \%$ & $53 \%$ \\
\hline
\end{tabular}

Elaboración propia con base en el análisis de los rotativos (enero-junio de 2015).

De ahí que se presenten fotografías con el encuadre, distancia y luz apropiados, de los cuerpos de quienes han perdido la vida, el poder de manipular su cuerpo, su imagen, su capacidad enunciativa y de decisión. Aquellos que ahora son cosificados y utilizados (violentando sus derechos como seres humanos) con la intencionalidad de terceros (reporteros, dueños y directivos) para promover la venta de un producto (el periódico), recibiendo a cambio la fascinación, horror, escándalo, reprobación, lástima, compasión o críticas de todo tipo, por parte de los espectadores y eventuales compradores que, a decir de unos, lo adquieren "para ver a los muertos y reírse de ellos". En cuanto al tratamiento que se da a los personajes distinguidos, se puede concluir que, como señala Ortiz (2008: 150-151), aun muertos se les quiere prolongar lo que se requiere fortalecer en el Más Acá, que no es otra cosa que creación humana, de esta forma el rico es un muerto rico y el pobre un pobre muerto y se les trata como tales.

Al principio parecía un poco difícil entender los criterios usados en la publicación de las fotos de cada uno de los casos. De igual manera parecía aventurado señalar que, en las decisiones en las que impera la cortesía, los reporteros habían tenido algunas "consideraciones" después de escuchar ciertas "sugerencias" de la familia, debido al respeto y admiración a los sujetos, al cariño o quizá también por el capital social amasado en vida. También era 
plausible pensar que, de la misma manera como se reservan las primeras páginas a los personajes distinguidos, sus fotos post mortem estuvieran consignadas a un manejo diferente a las del resto de la población. Para poder presentar un comentario más objetivo, se entrevistó a un reportero el cual señaló:

\begin{abstract}
Bueno, las únicas restricciones es cuando son celebridades, personajes importantes, se trata [pausa] no digamos con res [pausa] siempre hay respeto ¿no? Pero cuando uno que entra a los pormenores ¿¿sí?, cuando es un personaje así, de la burguesía o un político importante, un hermano de un político, oye pues se suicidó, punto ¿sí? en el otro, bueno pues si pones que se subió al árbol y la soga y cómo estaba amarrada y que si el surco apergaminado [pausa], entra uno más a los pormenores ¿no?, cuando son personas muy célebres, $\mathrm{mmmh}$ en términos de respeto, pero se puede plantear que con un poco más de respeto, sin entrar a los pormenores, sin ser tan [pausa] sin ser tan [pausa] sin ser tan violento en la descripción del evento.
\end{abstract}

De ahí que, un personaje distinguido en vida conserva su estatus e identidad intocables hasta la muerte y merece un lugar especial en el diario. Parten del supuesto que a la gente le interesa saber más, ya que no es lo mismo un muerto rico que un pobre muerto. Se procura su mejor foto en vida, como si el propio sujeto anunciara su nuevo estado desde el Más Allá.

Por otra parte, las fotografías aíslan las apariencias de un instante inconexo, por lo que requieren de una historia, para tener un significado, un pasado y un futuro que el reportero puede introducir desde el pie de la gráfica. La foto y el pie forman una historia que el lector puede entender sin necesidad de leer el texto completo que les acompaña. Luego, las fotografías con su pie constituyen un conjunto en los rotativos estudiados y, por lo general, tienen dos funciones diferentes dependiendo del lugar en el que se encuentren. Las de inicio de sección, en color, tienen como objetivo atraer la atención del lector a las páginas interiores, en las que se presenta la información completa, mientras que las de las páginas centrales, en blanco y negro, son concisas y ayudan al receptor a formar la historia. Vale seńalar que un buen número de los noti-reportajes de los tres rotativos violan tres de las máximas del Principio de Cooperación de Grice (1975), la de cantidad (haciendo su contribución más informativa de lo necesario), cualidad (expresando situaciones de las 
que no tienen evidencia suficiente) y manera (presentando la información de forma prolija y en ocasiones ambigua).

Ahora bien, como sabemos, los encabezados periodísticos, también conocidos como titulares o cabezas, influyen en el procesamiento de la información. Potter (2006) considera que son un resumen, pues dan una impresión general de la historia y son también un anuncio, pues le dicen al lector por qué es importante leer todo el noti-reportaje. Su objetivo básico es despertar la curiosidad del receptor, deben ser breves y atractivas ya que, además de la información que proveen, por medio del tamaño de letra indican la importancia de cada historia, a mayor tamaño más importante es la noticia.

Con relación a eso se debe recordar que el suicidio es un fenómeno multifactorial, ocasionado por la compleja interacción de muchos agentes como enfermedad física o mental, dependencia a ciertas substancias, disturbios familiares, conflictos interpersonales y situaciones estresantes en la vida cotidiana. Debido a esto, según la OMS, los medios de información impresa no deben reportar una causa única como responsable directa del suicidio. En algunos titulares es fácil identificar la presunta causa del suicidio, según el reportero, lo cual resulta impreciso, pues lo que presenta al lector como causa es sólo el detonador. Por otra parte, muchas veces la prensa atrae a sus lectores a través de sus encabezados y coberturas sensacionalistas al informar sobre los suicidios. Para ello, la OMS sugiere cuidar el uso de adjetivos calificativos, ya que éstos apoyan la transmisión, pero también la preservación de la información (verbal y no verbal) en la memoria colectiva; así como el uso de la metáfora, uno de los artificios léxicos más potentes, utilizado con propósitos emotivos y expresivos, según Ullmann (1965: 153). Ya que las metáforas no describen de manera directa, sino que construyen, reorganizan, descubren o desvelan nuevos elementos o establecen relaciones existentes en la realidad (Bustos, 2000:143). Así también, George Lakoff y Mark Johnson (Lakoff, G. y Johnson, M., 1986) señalan que nuestro mundo está estructurado conceptualmente y nuestro sistema conceptual es metafórico en su naturaleza; como ejemplo de lo anterior podemos señalar algunas frases de uso cotidiano "razones de peso", “ideas aplastantes", "negras intenciones”, entre otras. En los diarios estudiados se puede ver cómo utilizan los nombres propios de los suicidas, así como expresiones de moda, espectáculo y disfemismos para hacer sus encabezados "más atractivos". 
También con frecuencia se encuentran titulares en los que se nota una exuberancia del contenido discursivo al dar ciertos adelantos de los métodos e instrumentos utilizados: escopeta, cordón eléctrico, insecticida (si se puede hasta se menciona la marca), veneno (de preferencia también se incluye el nombre), cinturón, hilos de su hamaca, toalla, inyección, entre otros. En ocasiones, cuando se trata de ahorcamiento, señalan el objeto del que estaban pendiendo: tubo de una regadera, viga de su casa, tendedero. En caso de ahorcarse en un árbol, por lo general especifican el tipo de mata (ramón, zaramullo, naranja, ciruela, tamarindo). Y, en ocasiones se menciona hasta el color de la cuerda utilizada, así como el lugar donde se compró, además de otro tipo de información que -desde luego saben- puede resultar atractiva al lector.

En cuanto a su análisis, en el nivel nuclear se identifican los componentes y estructuras elementales de verosimilitud, iniciando con la referencial, que se inscribe en el ámbito de las relaciones del discurso con el mundo. Esto es, el discurso clasifica, organiza, da coherencia y estructura la realidad y las cosas que se retienen constituyen modelos conceptuales, los cuales contribuyen a constituir el mundo o la realidad. Y, ya que estos modelos se pueden captar en forma de metáforas, se realizó un análisis metaforológico, encontrando diferentes tipos. Entre las más socorridas se suman las metáforas estructurales, las cuales, como su nombre sugiere, estructuran la realidad, el modo como se piensa en ella y se describe. Se precisa resaltar que en ocasiones se utiliza más de una metáfora en los titulares periodísticos para presentar diferentes aspectos de un mismo o varios conceptos. Las listadas a continuación, utilizadas por diferentes reporteros de los tres rotativos seleccionados (el Por Esto! de manera principal), evidencian una concepción de la vida en términos de reclusión, soledad, opresión, limitación, imposición o sumisión, donde la metáfora que lo estructura es la del cautiverio, del cual se debe escapar. Ésta, a su vez, constituye una perífrasis que se utiliza con fines eufemísticos para presentar el suicidio como el tránsito por una puerta que permite la huida de un espacio vital, donde el objeto, "la puerta", se presenta como la opción, de entre varias para encontrar la muerte, en la que la acción de abrirla y atravesarla se sanciona por medio del modificador "falsa" que le añade el valor de "error" o "equivocación", contrario a lo real o verdadero. Ahora bien, en el sexto ejemplo de la siguiente tabla se presenta una variante, 
cambia el objeto "puerta" por "reja”, para agregar un significado connotado al estado del suicida en vida, quien estaba recluido en la cárcel. Cabe recordar que el uso de figuras literarias corresponde a la verosimilitud poética y su uso tiene como objetivo motivar la adhesión de los receptores, a través de su capacidad de emocionarse.

Además de lo anterior, se precisa señalar que la identidad del sujeto es un elemento prescindible en los titulares. En ocasiones se hacen excepciones, pequeñas concesiones, refiriéndose al suicida por su edad (joven), por la actividad desarrollada en vida (estudiantes, velador) o incluso por el apodo del sujeto en vida ("Motingas"), como para establecer la sensación de cercanía o empatía del reportero con la familia o amigos del suicida, lo cual además puede provocar alivio o catarsis en algunos lectores.

Tabla 8: ¿Vida como espacio de reclusión y suicidio como error?

\begin{tabular}{|c|c|c|}
\hline Encabezado & Rotativo & Fecha \\
\hline Escapa por la puerta falsa & Por Esto! & $\begin{array}{c}07 / 01, \\
04 / 02 \mathrm{y} \\
16 / 03 / 15\end{array}$ \\
\hline Velador escapa por la puerta falsa & Por Esto! & $31 / 03 / 15$ \\
\hline Escapa por la puerta falsa, en Kanasín & Por Esto! & $14 / 04 / 15$ \\
\hline Salió por la reja falsa & De Peso & $25 / 04 / 15$ \\
\hline Escapa por la puerta falsa: se ahorca & Por Esto! & $16 / 05 / 15$ \\
\hline "Motingas" escapa por la puerta falsa & Por Esto! & $25 / 05 / 15$ \\
\hline Sujeto de Tixkokob escapa por la puerta falsa & Por Esto! & $01 / 06 / 15$ \\
\hline Escapa por la puerta falsa una joven de Temax & Por Esto! & $01 / 06 / 15$ \\
\hline Joven decide salir por la puerta falsa & Por Esto! & $02 / 06 / 15$ \\
\hline Salió por la puerta falsa & ¡Al chile! & $03 / 06 / 15$ \\
\hline Joven estudiante escapa por la puerta falsa & Por Esto! & $18 / 06 / 15$ \\
\hline
\end{tabular}

Elaboración propia con base en el análisis de los rotativos (enero-junio de 2015).

Dichos ejemplos presentan dos modelos conceptuales, por un lado la vida como un espacio de reclusión, percepción lejana a la ideal para estructurar el pensamiento y actitudes de los lectores, y por el otro el suicidio como un error. Asimismo, cabe destacar que el apelar a los valores y configuraciones 
simbólicas aceptados por una mayoría, equivalente a la verosimilitud tópica, puede producir efectos de consenso en la sociedad, además de ser condición imprescindible para la efectividad de los otros tipos de verosimilitud señalados. Lo anterior, dadas las raíces culturales de muchos de los lectores, en particular las creencias religiosas, puede facilitar que el suicidio sea visto como un error. Esto, debido a que la mayoría de la población profesa la religión católica, la cual condena el suicidio, que representa sin duda el "mal morir" o "mala muerte". Además, en el caso de Yucatán la autoeliminación se da principalmente por ahorcamiento, la cual lleva una carga connotativa negativa adicional entre quienes profesan el catolicismo por la relación que guarda con el suicidio de Judas, el traidor en la Biblia. Ahora bien, un estudio sobre los actos perlocutivos puede revelar si la contigüidad de modelos (vida=reclusión y suicidio=error) ocasiona que, por influencia del segundo, se acepte el primero también.

Otra metáfora estructural muy socorrida por diferentes reporteros de dos de los diarios seleccionados ( $\mathrm{A} A$ l chile! y De Peso), presenta una concepción del suicidio en términos de romance, resaltando la seducción, enamoramiento y atracción hacia Ixtab, donde la metáfora que lo estructura es la del amor. Para facilitarla se vale de la verosimilitud poética, que al utilizar una figura literaria, la prosopopeya, atribuye actitudes humanas a un ente abstracto: "Ixtab" (diosa de los ahorcados), a quien se le asigna la capacidad de seducir, atraer y enamorar a un ser humano. Cabe recordar que los suicidas mayas contaban con esta diosa que los dirigía, paso a paso, por los laberintos de la muerte y les permitía ingresar a uno de sus trece cielos. Ixtab está representada con el rostro putrefacto (manchas negras en la mejilla y el pie) y los ojos cerrados, en el códice Dresde aparece con una cuerda en la garganta (I Vinteren pa Livet, 2015). De este modo, la concepción que se transmite sobre el suicidio es la de la consumación del amor.

El segundo encabezado de la tabla a continuación muestra además otra prosopopeya, "los problemas", los cuales aparecen como un ente amenazante que cobra fuerza y toma el control del individuo, al grado de llevarlo ante Ixtab. En este ejemplo se debe destacar la verosimilitud lógica, arte de persuadir y encadenar los significados ocultando el encadenamiento, la cual opera mediante el razonamiento y la argumentación en el plano ideológico del discurso. En éste se establece una relación de contigüidad, enlazando los 
significados de las dos situaciones (problemas = ir con Ixtab). El uso de estos recursos ańade elementos supuestos al titular.

Con respecto al tercer ejemplo, de la misma tabla, muestra otro rasgo de verosimilitud poética, pues 'echa mano' del tropo erotema, formulando una pregunta, cuyo objetivo no es obtener una respuesta del lector sino dar más fuerza a la afirmación sustentada, recalcar el poder de seducción de la diosa. En el cuarto caso además se introduce la palabra de origen maya "poch" que, en la situación que nos ocupa, se utiliza para indicar que la persona está entusiasmada o deseosa de parecer un vaquero. Sumado a lo anterior, se precisa resaltar que el primero y quinto de los titulares presentan un acto volitivo místico del suicida, mientras que en los otros la volición depende de los entes abstractos antes citados, Ixtab y los problemas.

Tabla 9: ¿Suicidio como consumación del amor a Ixtab?

\begin{tabular}{|l|c|c|}
\hline \multicolumn{1}{|c|}{ Encabezado } & Rotativo & Fecha \\
\hline Se enamoró de Ixtab & $i$ Al chile! & $04 / 02 / 15$ \\
\hline Sus problemas lo llevan con Ixtab & De Peso & $05 / 04 / 15$ \\
\hline ¿Ixtab seduce a extranjera? & De Peso & $26 / 05 / 15$ \\
\hline Ixtab sedujo a poch vaquero & $i$ Al chile! & $31 / 05 / 15$ \\
\hline Se fue con Ixtab & De Peso & $31 / 05 / 15$ \\
\hline
\end{tabular}

Elaboración propia con base en el análisis de los rotativos (enero-junio de 2015).

Por otra parte, la verosimilitud tópica en dichos ejemplos, además de ser condición imprescindible para la efectividad de los otros tipos de verosimilitud citados, puede producir consenso en parte de la sociedad. Esto, por la conexión del emisor (reportero/diario) con la base experiencial de los receptores (lectores), con quienes comparte los sistemas culturales y elementos comunes suficientes (pasado cultural de los mayas), para que la metáfora pueda estructurar su pensamiento y conducta. Lo anterior se sustenta en la invocación de valores incuestionables, como la existencia de la diosa maya del suicidio, quien anula la capacidad volitiva de los individuos al enamorarlos, con independencia de su sexo. Con ello parece enaltecerse el modelo conceptual del suicidio, presentándolo como el cenit del amor, donde el suicida aparece preso e indefenso ante los encantos de Ixtab. Como en los casos anteriores, las 
concepciones se transmiten por una figura de autoridad, el reportero, bajo el amparo del diario. Cabe señalar que, al utilizar estas percepciones, tomando en consideración que sirven para estructurar el pensamiento y actitudes de los lectores, se corre el riesgo de que algunos, con predisposición suicida, se adhieran a la tesis contenida en el encabezado.

En algunos titulares se incluyen también los nombres propios o apellidos de los suicidas, como recurso lingüístico, para estructurar una frase en la que se informa sobre su muerte. En ocasiones ésta sufre una variante, con tal de insertar el nombre o apellido del difunto. Cierto es que el uso de este procedimiento retórico puede causar alivio o catarsis en algunos lectores, atrayendo su atención a través de su capacidad de emocionarse, cuestión seguramente no acogida del mismo modo por los parientes y amigos del suicida. En el tercer ejemplo de la siguiente tabla, además de dicha función, se aprovecha el apellido del suicida para invocar la conocida figura retórica de la muerte, "la dama", a quien por lo general se le acompaña de un "caballero". Con dichos procedimientos retóricos, propios de la verosimilitud poética se da, además del humorístico, un toque eufemístico al noti-reportaje sobre el suicidio. No obstante lo anterior, la verosimilitud tópica se daría sólo entre los receptores que compartan los valores y configuraciones simbólicas reconocidas y aceptadas. De ahí que el desconocimiento de los nombres y apellidos de origen maya obstaculice, en ciertos lectores, la comprensión integral del mensaje en el encabezado.

Tabla 10: Multifuncionalidad de los nombres propios

\begin{tabular}{|l|c|c|}
\hline Encabezado & Rotativo & Fecha \\
\hline ¡Y se Matú! & De Peso & $23 / 01 / 15$ \\
\hline Yah se mató & De Peso & $22 / 04 / 15$ \\
\hline Caballero de la muerte & De Peso & $25 / 04 / 15$ \\
\hline
\end{tabular}

Elaboración propia con base en el análisis de los rotativos (enero-junio de 2015).

En el siguiente titular se utiliza el apodo del fallecido para reportar su deceso, quizá con el mismo afán que en las situaciones previas. Al igual que en el último caso, se alude a la muerte, aunque en éste se prefiere otra de las conocidas figuras retóricas para nombrarla, "la calaca", a la que se le atribuyen actitudes humanas, en particular femeninas, con la capacidad de atraer a los hombres 
y llevárselos con ella. Dicha forma discursiva evita nombrar lo innombrable, quizá por temor a invocarla al decir su nombre real, "la muerte", de la que hay que poner distancia pues no se está preparado para ese tránsito, además de ser un tabú para muchas personas.

Tabla 11: Apodos como recurso lingüístico

\begin{tabular}{|c|c|c|}
\hline Encabezado & Rotativo & Fecha \\
\hline "Flaco" se fue con la calaca & De Peso & $03 / 05 / 15$ \\
\hline
\end{tabular}

Elaboración propia con base en el análisis de los rotativos (enero-junio de 2015).

Por otra parte, en éste y el último ejemplo de la sección anterior, la verosimilitud tópica puede producir efectos de aprobación en los lectores, ya que los diversos nombres asignados a la muerte son del conocimiento/dominio público y el temor a enfrentarla es un valor compartido.

En lo que respecta a las expresiones coloquiales y títulos de canciones, recursos utilizados de manera principal por el rotativo $; A l$ chile!, se aprecia que en el primer titular de la siguiente tabla se prefiere, para atraer la atención y producir efectos en el colectivo de lectores, el uso de dos figuras retóricas para reportar el suicidio. Por un lado, la elipsis, donde dice "Literal... perdió la cabeza", la correcta construcción sería "De manera literal, la joven perdió la cabeza”. Con esto se logran varios objetivos: primero, la frase gana impacto, además de resaltar el uso de una expresión de moda "Literal", lo que equivale a reafirmar que los hechos ocurrieron tal cual se reportan en la conclusión de la frase "perdió la cabeza", esto es, conforme a la letra del texto, asignando el sentido exacto y propio, no figurado. Con ello también se da paso a otro tropo, la metáfora, en la que la imagen "perdió la cabeza" adquiere una transferencia de sentido, implicando que la persona se equivocó de manera monumental y significativa al optar por la autoeliminación. Así, al final se obtiene un doble mensaje, el figurado y el real, la joven tenía problemas personales en su vida y perdió (físicamente) la cabeza con el escopetazo que se dio.

En el siguiente encabezado: "Con la soga al cuello", se escoge una analogía que advierte que se está en una situación extrema y desesperada, por lo general de tipo económico. Ésta se basa en la pena capital efectuada por ahorcamiento. Su uso en el noti-reportaje cumple una doble función. Por un lado, toma el significado de la analogía, estar en aprietos económicos, lo cual corresponde al 
detonador del suicidio, pero es indicado como causa en el diario referido; por el otro, señala la forma seleccionada para la autoeliminación, el ahorcamiento. El uso de ésta, además de cumplir las funciones antes citadas, apela a los valores y configuraciones simbólicas compartidas por el reportero, los lectores y gran parte de la población.

El siguiente titular señala "El último trago", el cual, por sí mismo no ofrece información objetiva sobre el acontecimiento. No obstante, la lectura del texto completo revela la analogía que utiliza el reportero para referirse a dos experiencias similares, con objetivos distintos. Por un lado, el suicida estuvo ingiriendo bebidas embriagantes antes de tomar la determinación de autoeliminarse y después bebió un herbicida potente para poner fin a su vida.

Le sigue "Adiós, mundo cruel", el cual inicia con la interjección popular "Adiós", usada para despedirse cortésmente de alguien al retirarse de manera voluntaria de un lugar. Ésta se utiliza como introducción para después presentar una concepción de la vida en términos de estadía en un espacio, non grato, un lugar de residencia, que puede ser brutal y atroz. En ésta, la metáfora que lo estructura es la de una permanencia pasajera en un sitio que se puede abandonar, si se desea buscar la liberación. Sobra decir que el modelo conceptual que presenta de la vida no equivale a una percepción ideal para estructurar el pensamiento y actitudes de los lectores, ya que presenta la vida como estancia voluntaria en un lugar malo, del que se puede salir a placer. Cabe señalar que su uso no es original, pues ya en 1962, el baladista mexicano, Enrique Guzmán cantaba una canción con ese título en español.

En el quinto se prefiere una variante de una expresión coloquial utilizada en lugar de "morir", "estirar la pata", derivado del conocimiento que revela que cuando un ser muere quedan "restos" de electricidad en el cuerpo, lo que hace que se manden impulsos nerviosos hacia las extremidades, produciendo su estiramiento. En cualquier caso, se trata de un disfemismo, ya que bien podrían utilizarse otras expresiones, también coloquiales y de carácter eufemístico como "pasar a mejor vida" o "dar el último suspiro". No obstante, para darle un toque menos duro se cambia "pata" por "patrulla". Amén de lo anterior, se elige el término coloquial "gringa", femenino de "gringo", para identificar a una mujer originaria de los Estados Unidos de América. Palabra, en principio despectiva, cuyo origen, según teoría del diccionario Manual de Sinónimos y Antónimos de la Lengua Española, se 
remonta a la canción "Green Grow the Rushes-oh", que cantaban los soldados norteamericanos en la guerra entre México y Estados Unidos en 1846-1848. Tanto la expresión como el término son configuraciones simbólicas aceptadas por buena parte de los lectores de dicho diario, mexicanos, principalmente del sureste del país, de clase media baja o baja y con un nivel de estudios elemental. Cabe destacar que su uso refuerza dicho sistema conceptual. Ahora bien, se debe resaltar que la expresión en sí no alude directamente a la forma de morir, autoeliminación.

Tabla 12: Expresiones coloquiales y títulos de canciones

\begin{tabular}{|l|c|c|}
\hline \multicolumn{1}{|c|}{ Encabezado } & Rotativo & Fecha \\
\hline Literal...perdió la cabeza & $i$ Al chile! & $06 / 01 / 15$ \\
\hline Con la soga al cuello & $i$ Al chile! & $05 / 01 / 15$ \\
\hline El último trago & $i$ Al chile! & $19 / 02 / 15$ \\
\hline Adiós, mundo cruel & De Peso & $21 / 03 / 15$ \\
\hline Gringa estira la patrulla & $i$ Al chile! & $26 / 05 / 15$ \\
\hline
\end{tabular}

Elaboración propia con base en el análisis de los rotativos (enero-junio de 2015).

Existen casi tantos ejemplos de usos de estas figuras como noti-reportajes del suicidio publicados en los diarios de este estudio, donde el común denominador es el suicida quien, sin proponérselo, contribuye a la venta del rotativo. Y éste puede desempeñar diferentes roles, como se ha visto a lo largo del análisis. Uno más, en el encabezado "No le dio mucho el sol, se pudrió" publicado el 25 de abril de 2015 en jAl chile!, se ve cómo a través de una analogía se evidencia la concepción del cuerpo del suicida como un ser sin voluntad ni deseos, dependiente de la energía del astro rey para mantenerse en óptimas condiciones. En éste, la metáfora que lo estructura pareciera ser la de un vegetal, concretamente una planta de sol, la cual al estar a la sombra termina por marchitarse o pudrirse. Encabezado en el que, además, se prefiere el uso de un disfemismo, "se pudrió", para referirse al suicida, pues bien se podría decir que el cuerpo está en descomposición o corrompiéndose lo cual, con toda seguridad, no causaría el mismo efecto en el lector.

Como se explicó desde el inicio, las publicaciones sobre el suicidio son un híbrido; esto es, comparten las características de los géneros informativos 
e interpretativos, en donde en los primeros se toma distancia con respecto a la información, mientras que en los segundos el diario deja su función de mediador (en ocasiones depositando esta función en sus colaboradores) para convertirse en un actor social. Derivado de esto, es importante resaltar que en todos los casos las concepciones relacionadas con la información sobre un suicidio se transmiten por el reportero, quien estructura el discurso y representa una figura calificada y de autoridad para el receptor, no sólo por su formación y experiencia en el campo de la comunicación, sino también por el respaldo que le brinda el rotativo. De ahí que en la autoconstrucción del hablante, el periodista o reportero se erige como representante o voz autorizada de un grupo social, los lectores de dichos diarios. De esta forma, él tiene la palabra para sentenciar lo que es bueno o malo y puede ejercer cierta influencia en los lectores, situación que podría comprometer a los individuos vulnerables, con ideación suicida.

\section{Consideraciones finales}

Para empezar, tras la revisión de las publicaciones sobre suicidios se confirma que siguen sin observarse las sugerencias que publicó la OMS desde el 2000. Entre el 33 y 36\% de las publicaciones sobre el suicidio en los rotativos del estudio no presentó fotografías durante el periodo, no obstante los 63 notireportajes restantes incluyeron 128 fotografías en sus artículos. Asimismo, el número de columnas asignadas a los noti-reportajes sigue rebasando los límites sugeridos. También, se siguen reportando más casos de autoeliminación de los que hay, debido a la repetición de la noticia a varios días de ocurrido el hecho. A lo anterior se debe agregar la propuesta de la OMS de evitar que los medios de información impresa reporten una causa única como responsable directa del suicidio. Situación contraria a lo encontrado en los rotativos, donde se declaran cuáles son las causas del suicidio, sin considerar que lo reportado equivale tan sólo a lo que perciben, el detonador.

Así, este análisis de las publicaciones sobre suicidios, tomadas en los primeros seis meses de 2015 de los diarios seleccionados, muestra un elemento más de la cadena de violencia representada por los medios informativos impresos en sus discursos (verbales y no verbales). Monsiváis (2010:7) señalaba que reporteros y diarios parecían preocuparse por lograr en el lector un engranaje perfecto entre el horror inducido y el placer controlado. Luego, para lograrlo 
hacen acopio de las mejores fotografías de los suicidas (in situ, muertos y descubiertos de preferencia o por lo menos en vida, aunque las gráficas no sean tan recientes), se incluyen ríos de sangre y putrefacción, se sofoca a las fuentes (para obtener tantos pormenores como sea posible) o incluso se deja que se cuelguen del suicida (parientes, amigos vecinos o autoridades). Y, en ocasiones, también se procura exhumar acontecimientos y personajes para lograr más columnas en el rotativo y desde luego, que los encabezados sean lo suficientemente "atractivos" para atraer a los posibles lectores.

Por otra parte, así como la información sobre el suicidio vende mucho, las fotografías parecen aumentar el valor de cambio del ejemplar, pues según señalan los reporteros la gente las busca y -como se comprobó en entrevistas realizadas en un estudio previo- sienten cierta fascinación al ver la muerte tan de cerca, con la probable satisfacción de no ser las víctimas, lo cual no es privativo de la comunidad de estudio, según señala Crettiez (2009: 61). No obstante, lo que publican en los periódicos son puestas en escena, en las que muestran u ocultan situaciones de acuerdo con la percepción, preferencia o criterio del reportero. Así presentan al lector actores y escenografías con mensajes connotados que los receptores deben descifrar, identificar lo que se ve, tratar de definir lo que no se ve, determinar la razón de esto y quizá establecer la intención real del reportero o diario en cuestión.

En algunos casos los reporteros llegan al lugar de los hechos y se apoderan momentáneamente del cuerpo, cosifican al suicida, lo utilizan como promotor del rotativo, obviando la violencia que significa esta apropiación y manipulación. El fallecido recibe un tratamiento distinto al de una persona en vida, ahora se le maneja bajo reglas diferentes (impuestas) para los difuntos, quizá debiera decir específicas para los suicidas pobres, en las que al parecer el sujeto pierde los derechos que tenía en vida (al fin ya no puede protestar). Con esto se muestra que aun muertos están insertos en una cadena de violencia en la que les toca jugar el papel de víctimas, esta vez por la dimensión identitaria selectiva, ya que con este tratamiento se les niega la identidad que merecen, despojándolos de su humanidad y reduciéndolos a simples objetos a disposición del victimario (fotógrafo, reportero, rotativo).

Por lo que se refiere al discurso, se utiliza para guiar la percepción del lector a través de la conformación de modelos conceptuales por medio del uso de metáforas y otras figuras como la prosopopeya y los erotemas. Asimismo, se 
inducen los efectos de consenso en la sociedad mediante el uso de valores y configuraciones simbólicas aceptados por un grupo de la población.

Queda mucho trabajo por hacer; no obstante, entre los pendientes se suma la promoción de acciones propositivas, como el acercamiento a los medios impresos de comunicación con objeto de sensibilizarlos y tratar de encontrar un balance entre el manejo de estrategias discursivas en el rotativo, que les permita vender las noticias y observar las recomendaciones de la OMS. Para ello, podría iniciarse con reuniones y cursos en los que participen tanto los reporteros como los profesionales y académicos relacionados con el tema: antropólogos, analistas del discurso, psicólogos, psiquiatras, sociólogos, por citar algunos. Por último, vale decir que se está conformando una Red de especialistas contra la violencia en el sureste de México, concretamente en los tres estados de la Península. 


\section{Bibliografía citada}

Anda, Sonia de, (2015) "Dos décadas de ayuda espiritual y emocional", en Milenio. 11 de julio de 2015. Yucatán. Recuperado de: http:// sipse.com/milenio/salvemos-una-vida-aniversarios-festejoyucatan-160707.html

Berger, John y Jean Mohr, (2007) Otra manera de contar. Barcelona: Editorial Gustavo Gili.

Bustos, Eduardo, (2000) La metáfora: ensayos transdisciplinares. Madrid: F.C.E. Crettiez, Xavier, (2009) Las formas de la violencia. Buenos Aires, Argentina: Waldhuter Editores.

Gálvez Vidal, Germán, (2010) “Reglas publirreportajes”, en Nuevos Periodistas. México. (en línea). Recuperado de: http://habilidadesperiodisticas.blogspot.com/2010/02/empresas-en-reforma-seccion-comercial. html

Grice, Herbert Paul, (1975) Logic and conversation en Cole, Peter y Jerry L. Morgan (ed.), Syntax and semantics: Speech acts, Volume 3, pp.41-58, New York: Academic Press.

Hernández Ruiz, Laura, (2011) Percepciones del suicidio en Chichí Suárez, Yucatán, y el discurso utilizado para reportarlo en el diario Por Esto!, Tesis de Doctorado en Antropología, UNAM.

I Vinteren pa Livet, (2015). Psicopompos: Ixtab. Arqueología de la Muerte. Recuperado de: https://vinterenlivet.wordpress.com/2015/07/22/ psicopompos-ixtab/ (Consultada el 0304 2019)

Ibáñez, Jesús, (1979) Más allá de la sociología: El grupo de discusión: teoría y crítica. México: Siglo XXI.

Instituto Nacional de Estadística y Geografía, (2005) Estadísticas de intentos de suicidio y suicidios, Serie boletín de estadisticas continuas, demográficas y sociales. México: INEGI (en línea). Recuperado de: http://internet. contenidos.inegi.org.mx/contenidos/productos//prod_serv/contenidos/espanol/bvinegi/productos/continuas/sociales/suicidio/2005/ BoletinSui05.pdf.

Instituto Nacional de Estadística y Geografía, (2009) Estadística de suicidios de los Estados Unidos Mexicanos 2008. Aguascalientes, México: INEGI (en línea). Recuperado de: http://internet.contenidos.inegi.org. 
$\mathrm{mx} /$ contenidos/Productos/prod_serv/contenidos/espanol/bvinegi/ productos/continuas/sociales/suicidio/2008/suicidios_2008.pdf

Instituto Nacional de Estadística y Geografía, (2011) Estadística de suicidios de los Estados Unidos Mexicanos 2009. Aguascalientes, México: INEGI (en línea). Recuperado de: http://internet.contenidos.inegi.org. $\mathrm{mx} /$ contenidos/Productos/prod_serv/contenidos/espanol/bvinegi/ productos/continuas/sociales/suicidio/2009/suicidios_2009.pdf.

Instituto Nacional de Estadística y Geografía, (2012) Estadística de suicidios de los Estados Unidos Mexicanos 2010. Aguascalientes, México: INEGI (en línea). Recuperado de: http://internet.contenidos.inegi.org. $\mathrm{mx} /$ contenidos/Productos/prod_serv/contenidos/espanol/bvinegi/ productos/continuas/sociales/suicidio/2010/suicidios_2010.pdf.

Instituto Nacional de Estadística y Geografía, (2013) Estadística de suicidios de los Estados Unidos Mexicanos 2011. Aguascalientes, México: INEGI (en línea). Recuperado de: http://internet.contenidos.inegi.org. $\mathrm{mx} /$ contenidos/Productos/prod_serv/contenidos/espanol/bvinegi/ productos/continuas/sociales/suicidio/2011/702825047436.pdf.

Instituto Nacional de Estadística y Geografía, (2005, 2011, 2012, 2013, 2014) Mortalidad. Recuperado de: http://www.inegi.org.mx/sistemas/olap/Proyectos/bd/continuas/mortalidad/MortalidadGeneral. asp?s=est\&c=11144\&proy=mortgral_mg (septiembre a octubre de 2016)

Jociles Rubio, María Isabel, (2005) El análisis del discurso: de cómo utilizar desde la antropología social la propuesta analítica de Jesús Ibáñez en Avá: Revista de Antropología, número 7, pp. 1-25. Argentina: Universidad Nacional de Misiones.

Lakoff, George y Mark Johnson, (1986) Metáforas de la vida cotidiana. Madrid: Cátedra.

Marzuk, Peter M. y Kenneth Tardiff, (1995) Increase in Suicide by Asphyxiation in New York City after the Publication of Final Exit en Publishing Research Quarterly. Winter94/95, Vol. 10 Issue 4, p63. http:// eds.b.ebscohost.com/eds/pdfviewer/pdfviewer?vid=3\&sid=3ac9c0cca1c1-4ed6-a7e8-7574d0707069\%40pdc-v-sessmgr05 
Ministerio de educación, (s/f) "Estructura de la noticia". Media Prensa. España. (en línea). Recuperado de: http://recursos.cnice.mec.es/media/ prensa/bloque3/pag6.html [consultado el 2 de octubre de 2016].

Monsiváis, Carlos, (2010) Los mil y un velorios. Crónica de la nota roja en México. Debate, México.

Muchembled, Robert, (2002) Historia del Diablo Siglos XII-XX. México: FCE. Murmurante (s/f), "Nosotros". en Murmurante. (en línea). Recuperado de: http://www.murmurante.org/nosotros.html

Organización Mundial de la Salud (OMS), (2000) Prevención del Suicidio: Un Instrumento para Profesionales de los Medios de Comunicación. Disponible en http://www.who.int/mental_health/media/media_spanish. pdf [Fecha de consulta: 10 septiembre 2012].

Ortiz Aguirre, Víctor Manuel, (2008) Máscaras de la Muerte. México: El Colegio de Michoacán.

Pericot, Jordi, (2002) Mostrar para decir: La imagen en contexto. Barcelona, España: Universidad Autónoma de Barcelona (Colección Aldea Global 13).

Potter, Deborah, (2006) Manual de periodismo independiente. p. 34-36, Washington, D. C.: NewsLab, Disponible en www.newslab.org

Schmidtke Armine, Schaller Sylvia, (2002) "What do we do about media effects on imitation of suicidal behaviour” En D. De Leo, A. Schmidtke, R. F. W. Diekstra (ed.), Suicide prevention. A holistic approach. pp. 121-137. Netherlands: Springer .

Secretaría de Gobernación, (2018) Padrón Nacional de Medios Impresos 2016. Recuperado de: http://pnmi.segob.gob.mx/ (Fecha de consulta: 10 de octubre de 2016).

Secretaría de Salud de Yucatán, (2018) "Programa para la Atención a la Depresión y Prevensión del Suicidio (PDS)”, en Catálogo de Programas de bienes y servicios públicos 2015. México. (en línea) Recuperado de: http://salud.yucatan.gob.mx/wp-content/uploads/2013/03/ Cat\%C3\%A1logo_de_Programas_SSY.pdf

Soubrier, Jean-Pierre, (1984) La prevention du suicide est-elle encore possible depuis la publication autorisée d'un livre intitulé: suicide Mode d’Emploi - Histoire, Techniques, Actualités en Prevención del suicidio, 
un recurso para los profesionales de los medios. Ginebra: Organización Mundial de la Salud.

Stack, Steven y Haas, A. (1984) The Effect of unemployment duration on national suicide rates: A time series analysis, 1948-1982 en Sociological Focus, año 17, núm. 1, pp. 17-29.

Taller de Redacción, (2009) Cabezas o titulares. El Blog de Joaquin Pérez. (en línea) 23, junio, 2009. Recuperado de: http://tallerderedaccion.overblog.com/article-33005053.html

Ullmann, Stephen, (1965) Semántica: Introducción a la ciencia del significado. Madrid: Aguilar.

Verón, Eliseo, (1980)La semiosis social en El Discurso Politico. México: edición de Monteforte Toledo, UNAM, Nueva Imagen, pp. 145-165 